PROCEEDINGS

JOINT CONVENTION YOGYAKARTA 2019, HAGI - IAGI - IAFMI- IATMI (JCY 2019)

Tentrem Hotel, Yogyakarta, November $25^{\text {th }}-28^{\text {th }}, 2019$

\title{
Rock Mass Characterization And Rock Failure Probability Analysis of Rock Mining Areas at Lagadar, Bandung Regency and Batujajar, West Bandung Regency, West Java
}

Rachman, F. R. ${ }^{1}$, Dinata, I. D. ${ }^{2}$ and Sadisun, I. S. ${ }^{2,3}$

${ }^{1} P T$ Quantus Consultants Indonesia

${ }^{2}$ Applied Geology Research Group, Faculty of Earth Sciences and Technology, Institut

Teknologi Bandung

${ }^{3}$ Research Center for Disaster Mitigation, Institut Teknologi Bandung

E-mail: indraandradinata@gmail.com

\begin{abstract}
Research area is located at coordinates $6^{\circ} 53^{\prime} 56^{\prime \prime}$ $\mathrm{S}, 107^{\circ} 30^{\prime} 10^{\prime \prime} \mathrm{E}$ up to $6^{\circ} 56^{\prime} 8^{\prime \prime} \mathrm{S}, 107^{\circ} 32^{\prime} 15^{\prime \prime}$ E which administratively covers Lagadar, Bandung Regency and Batujajar, West Bandung Regency, West Java. The research area is a rock mining area that is still being mined actively today. This research aims to characterize the rock mass, analyze rock failure probability, and optimize the slope excavation at the rock mining area.

The conducted methods of this research are field observation, rock sampling, and scanline survey at 5 sites. The sites are F-5, F-10.1, F-10.2, F-11, and F-12. Quantitative method is conducted to characterize the rock mass, followed by analysis of rock failure probability with kinematic analysis method, and excavation optimization using kinematic analysis scenarios.
\end{abstract}

\section{Introduction}

The hills that extend around Lagadar and Batujajar areas are used as rock mining areas. However, conditions in the field found that several mining areas carried out the exploitation process using methods that paid little attention to the safety aspects of their workers. Besides, there is also a hazard caused by exploited rock slopes, for example, rock slope instability. Not all mining companies or communities pay attention to aspects of Engineering Geology in their mining planning. If rock collapse occurs in the excavation area, the threat will be related to the safety of workers, heavy equipment, and production activities.

The research location is located in the rock mining area of 5 slopes spreaded around Batujajar, West
Field observation obtained the rock type of site F5, F-10.1, and F-10.2 are andesite; site F-11 is breccia; and site F-12 is dacite. Index test results the average range of Schmidt Hammer Rebound Value (SHRV) is 40,25-63,05. Physical property test results the value range of unit weight is 22,96 $\mathrm{kN} / \mathrm{m}^{3}-26,03 \mathrm{kN} / \mathrm{m}^{3}$ and porosity is $1,92 \%-$ $3,78 \%$. RMR rock mass characterization results the RMR total value of all sites are "good" category. Rock failure probability analysis on all sites results the major failure is wedge failure at $14,65 \%-38,97 \%$. SMR analysis results the slope of all sites are "good" category. Optimization of dip angle excavation is $65^{\circ}$.

Keywords: scanline, rock mass, RMR, SMR.

Bandung Regency and Lagadar, Bandung Regency. The coordinates of the study area are at 776574 E, $9236694 \mathrm{U}$ up to $780413 \mathrm{E}, 9232659 \mathrm{~N}$ (in UTM coordinates with 1984 WGS datum and $48 \mathrm{~S}$ zone) (Figure 1). Furthermore, the five slopes are called F-5, F-10.1, F-10.2, F-11, F-12 (Figure 2). 

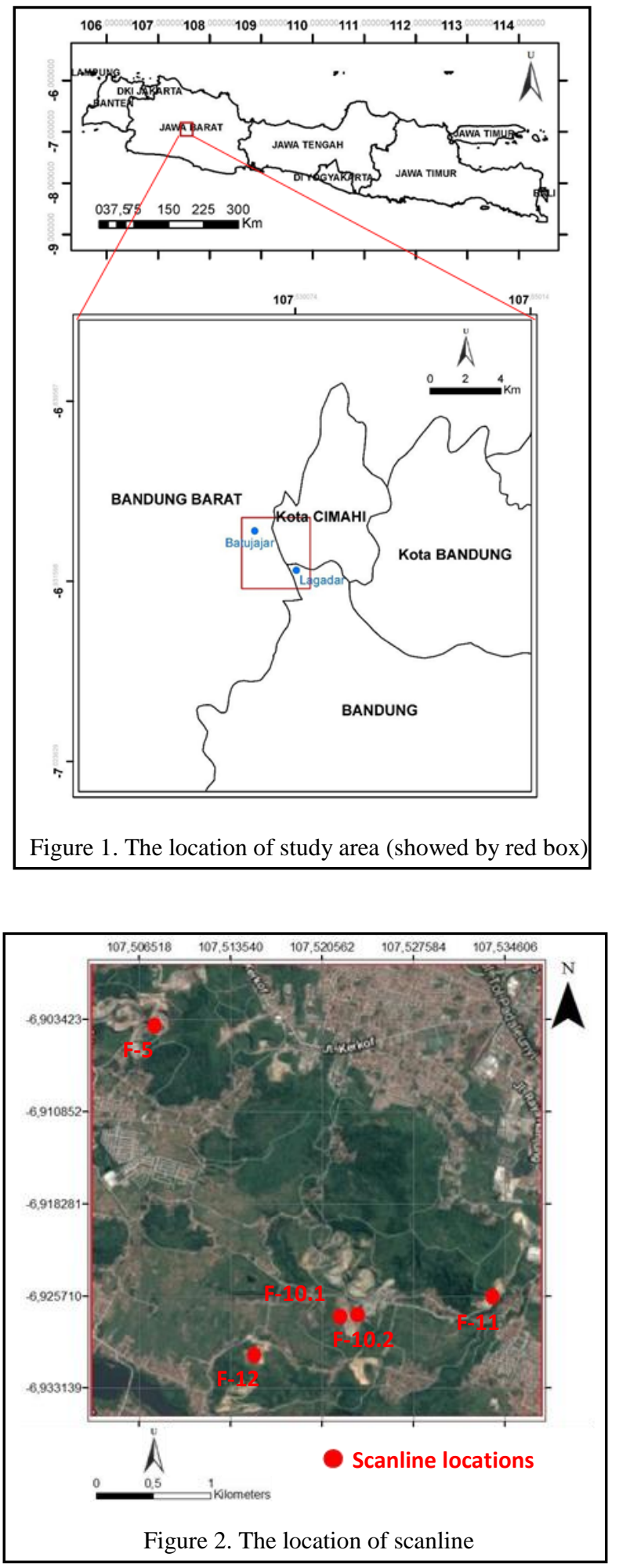

The objective of this paper is to perform rock mass characterization using Rock Mass Rating (RMR) and Slope Mass Rating (SMR) rock mass classification methods and the rock collapse probability analysis using kinematics analysis methods. The final results of this study are in the form of an explanation of the geological conditions, the total value of the RMR, the total value of the SMR, and the conclusions of the entire discussion. The results of this study are expected to be useful as consideration for planning rock mining activities.

\section{Methods}

The method used in this study consisted of observing the geological conditions in the field, observing the rock slopes visually, observing lithology macroscopically, testing carried out in the field, scanline surveys at the locations of the research, testing carried out in the laboratory, conducting analysis probability of collapse using kinematics method, and rock mass characterization with Rock Mass Rating (Table 1) and Slope Mass Rating methods (Table 2).

Table 1. Rock Mass Rating (RMR) parameters determination (Bieniawski, 1989)

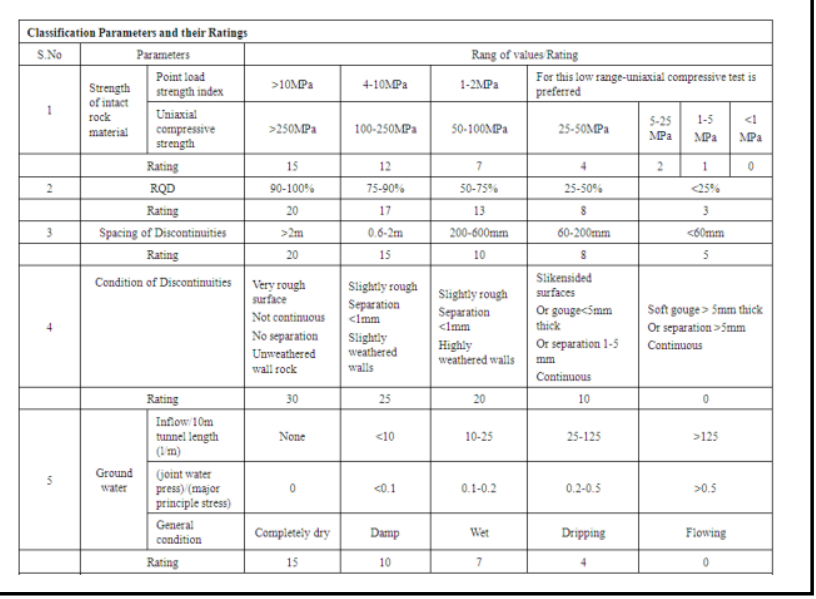


PROCEEDINGS

JOINT CONVENTION YOGYAKARTA 2019, HAGI - IAGI - IAFMI- IATMI (JCY 2019)

Tentrem Hotel, Yogyakarta, November $25^{\text {th }}-28^{\text {th }}, 2019$

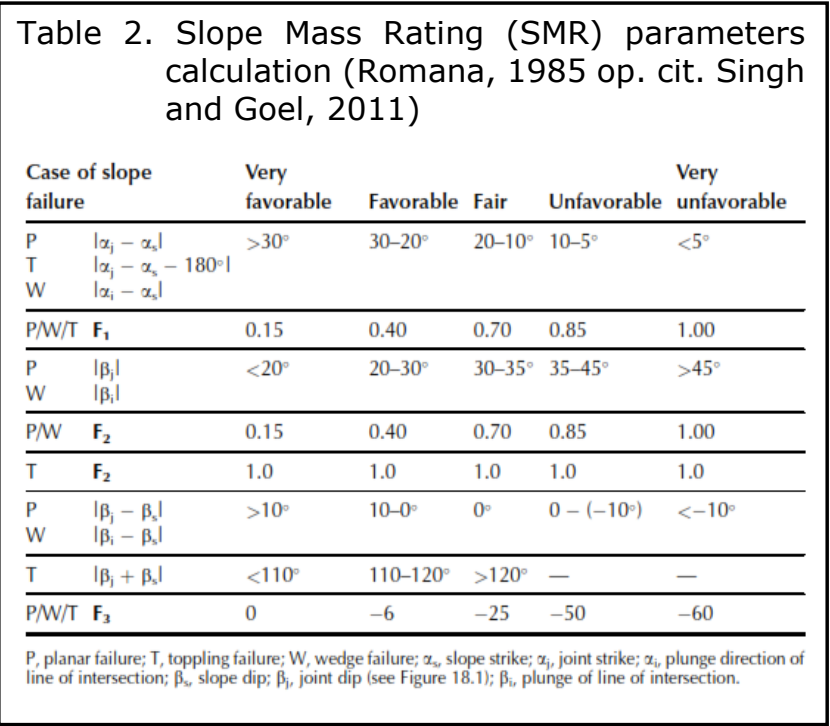

\section{Geological conditions}

The research area is on the Geological Map of Bandung, West Java (Silitonga, 1973). Physiographically, the research area lies in the
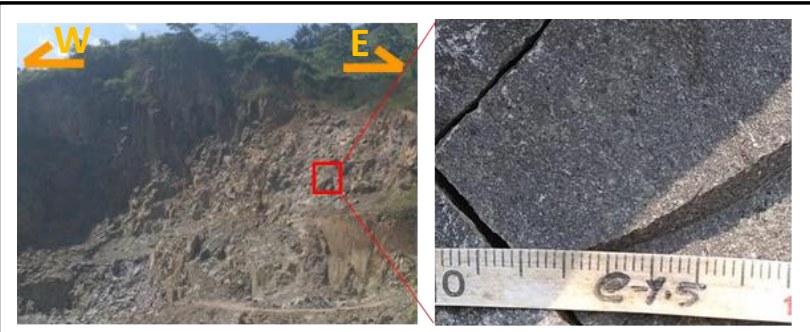

Figure 3. Lithology condition at F-5

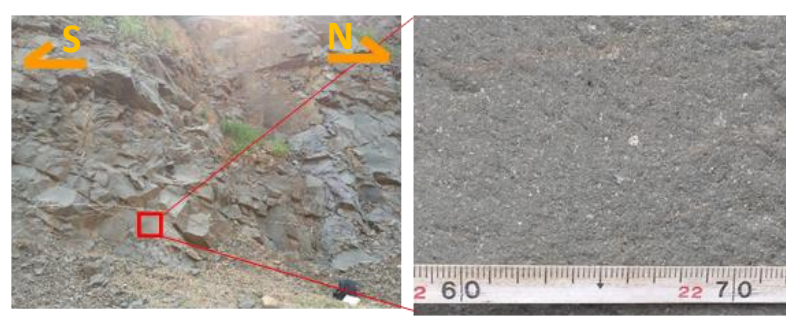

Figure 4. Lithology condition at F-10.1 and F-10.2
Central Depression Zone of West Java (van Bemmelen, 1949). The depression zone had been

intruded by volcanic cones since Tertiary to Quaternary. The volcanic arc area referred to as the Bandung Zone is flanked by the Bogor Zone in the north and the Southern Mountains zone in the south.

According to Dam (1994), the morphogenic classification of the research area is included in the Volcanic and Tectonic Earth Face Unit with Intrusive Subunit which consists of hills or ridges which are mainly formed from endogenous intrusion processes and generally consist of igneous rocks (volcanic necks from andesite, dacite, or basaltic, as well as breccia). This unit forms the central part of volcanic cones with steep reliefs and clear landscapes.

The five research sites have various types of lithology, including locations F-5, F-10.1, and F10.2 have andesite lithology types (Figure 3 and 4 ); location of F-11 has breccia type (Figure 5); and the location of the F-12 has a dacite type (Figure 6).

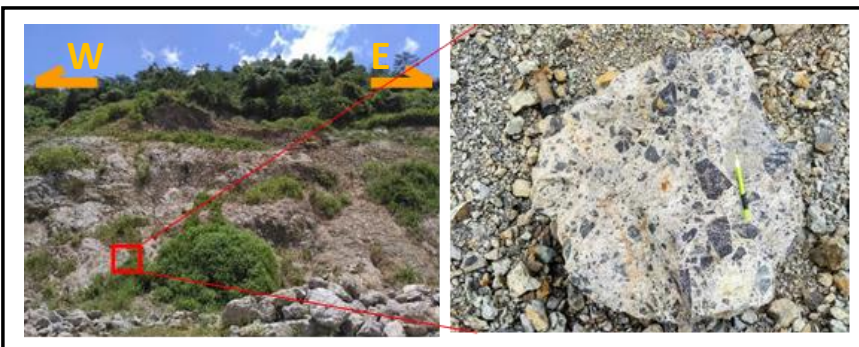

Figure 5. Lithology condition at F-11

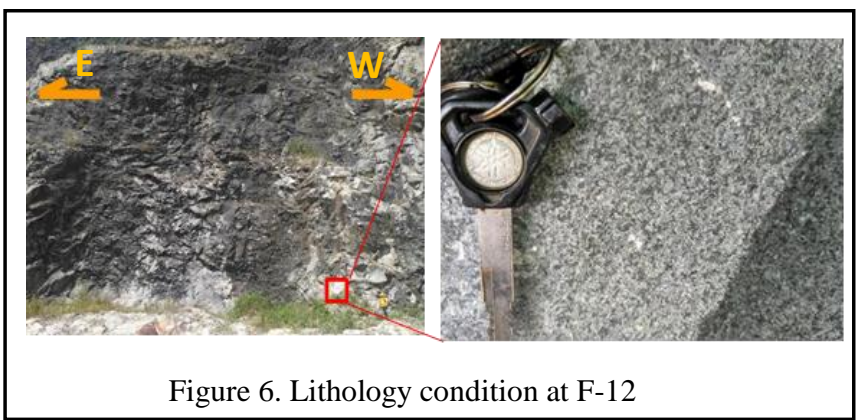


PROCEEDINGS

JOINT CONVENTION YOGYAKARTA 2019, HAGI - IAGI - IAFMI- IATMI (JCY 2019)

Tentrem Hotel, Yogyakarta, November $25^{\text {th }}-28^{\text {th }}, 2019$

\section{Result and Discussion}

4.1 Rock Mass Characterization using the Rock Mass Rating (RMR) Method

Data on rock mass conditions and discontinuities are then weighted according to the RMR parameters consisting of uniaxial compressive strength (UCS), RQD, inter-discontinuity distance, discontinuity conditions, and groundwater conditions. The presentation of data in the form of a table of values and weightings below is the average value at that location.

The UCS value is obtained from the approach of the SHRV (Schmidt Hammer Rebound Value) derived from the field test of rock index properties. From the weighting of the UCS values in each location, almost all locations are weighted by 12 or very strong, except for the location of F-11 which is 7 or strong. This is certainly following the rock conditions where the F-11 location is composed of breccia.

Based on the results of calculations and weighting, the RQD values in all scanline locations have an average range of $80.77 \%$ (good)-95.43\% (excellent). The lowest RQD value at the F-5 location and the highest value at the F-11 location.

From the results of the calculation and weighting of the inter-discontinuity distance values, the average range is between $0.17 \mathrm{~m}$ (moderate)-0.6 m (close).

Discontinuity conditions are obtained from the description of each discontinuity. Based on observations and measurements, the length of discontinuities in the study area is $<1 \mathrm{~m}$ and $1-3$ $\mathrm{m}$, has aperture of $0.1 \mathrm{~mm}-1 \mathrm{~mm}$, smooth-rough discontinuities, fill conditions from non-filling to soft stuff $<2 \mathrm{~mm}$, and the weathering conditions are all moderately weathered. The total weighting of all discontinuity conditions has a range of values 18 to 22 .

Based on observations in the field, it was found that groundwater conditions at all locations were dry.

The calculation uses the total RMR equation, which sums all the weight values on each parameter. From the calculation results, the total value of the RMR is 71.2-73.9. The range of values indicates that the RMR class in all locations is "good" (Table $3)$.
Based on the RMR value, it can be concluded that the safe cut slope for all slopes is $65^{\circ}$ (Waltham, 2002 op. cit. Singh and Goel, 2011).

\begin{tabular}{|c|c|c|}
\hline \multicolumn{3}{|c|}{ Table 3. Total RMR Value } \\
\hline Location & RMR & Class \\
\hline F-5 & 71,8 & Good \\
\hline F-10.1 & 71,2 & Good \\
\hline F-10.2 & 73,9 & Good \\
\hline F-11 & 71,6 & Good \\
\hline F-12 & 71,3 & Good \\
\hline
\end{tabular}

4.2 Rock Mass Characterization using the Slope Mass Rating (SMR) Method

Analysis of the kinematics performed resulted in the overall slope having the highest probability of collapse in wedge type, so the subsequent calculation of the SMR used the SMR equation on the type of wedge collapse.

The F1 values are obtained based on the calculation of the relationship between discontinuity plane and slope plane. From the calculation results, it was found that the F1 value at all locations was 0.15 (very good) -0.37 (good). The F1 value with the description "very good" is only at location F-10.2 (Table 4).

The F2 values are obtained based on the dip of the discontinuity. From the calculation results, it was found that the description of the F2 value in all locations was "very bad" with a value range of 0.95-0.98 (Table 4).

The F3 value is obtained based on the calculation of the relationship between the dip of the discontinuity and the dip of slope. From the results of calculations, it was found that the description of the value of $F 3$ in all locations was "very good" with a range of values $(-0.6)-(-2.5)$ (Table 4$)$.

The value of $\mathrm{F} 4$ is derived from the type of excavation applied to the slope. The type of excavation in all locations is mechanical excavation so that the value of $\mathrm{F} 4$ at all locations is 0 (Table 4).

Calculation of the total value of the SMR and producing the range of SMR values at all locations is 68.85-75.13. This shows that the description of the SMR value in all locations is "good" (Table 4). 
PROCEEDINGS

JOINT CONVENTION YOGYAKARTA 2019, HAGI - IAGI - IAFMI- IATMI (JCY 2019)

Tentrem Hotel, Yogyakarta, November $25^{\text {th }}-28^{\text {th }}, 2019$

Table 4. SMR Parameter and Total Value Calculation

\begin{tabular}{|l|l|l|l|l|l|l|}
\hline Location & F1 & F2 & F3 & F4 & SMR & Description \\
\hline F-5 & 0,36 & 0,98 & $-2,5$ & 0 & 70,32 & Good \\
\hline F-10.1 & 0,37 & 0,96 & $-2,5$ & 0 & 68,85 & Good \\
\hline F-10.2 & 0,15 & 0,97 & $-0,6$ & 0 & 72,13 & Good \\
\hline F-11 & 0,35 & 0,95 & $-0,6$ & 0 & 71 & Good \\
\hline F-12 & 0,31 & 0,97 & $-2,5$ & 0 & 75,13 & Good \\
\hline
\end{tabular}

\section{Conclusion}

- $\quad$ Field observation obtained the rock type of site F-5, F-10.1, and F-10.2 are andesite; site $\mathrm{F}-11$ is breccia; and site $\mathrm{F}-12$ is dacite.

- RMR rock mass characterization results the RMR total value of all sites are "good" category with RMR range value between 71.20-73.90.

- $\quad$ SMR analysis results the slope of all sites are "good" category with SMR range value between 68.85-75.13.

- Optimization of dip angle excavation based on RMR vale is $65^{\circ}$ for all locations.

\section{References}

Bieniawski, Z.T. (1989): Engineering Rock Mass Classification: A complete Manual for Engineers and Geologists in Mining, Civil, and Petroleum Engineering, Wiley-Interscience Publications, Canada, 251 pages.

Dam, M.A.C. (1994): The late quaternary evolution of the Bandung Basin, West Java, Indonesia, Doctor Disertation, Vrije Universiteit Amsterdam, 252 pages.

Hudson, J.A. and Harrison, J.P. (1997): Engineering Rock Mechanics: An Introduction to The Principles, Elsevier, Oxford, 444 pages.

Silitonga, P.H. (1973). Peta Geologi Lembar Bandung skala 1:100.000, Puslitbang Geologi, Bandung.

Singh, B. and Goel, R.K. (2011): Engineering Rock Mass Classification: Tunneling, Foundation, and Landslides, Elsevier, United Kingdom, 365 pages. van Bemmelen, R.W. (1994): The Geology of Indonesia, Government Printing Office, The Hague, 732 pages. 